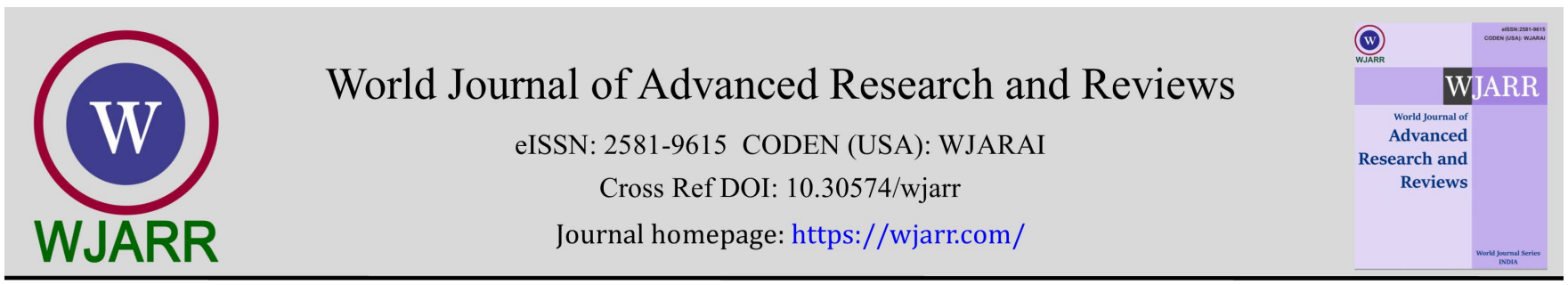

(REVIEW ARTICLE)

Check for updates

\title{
The resurgence of black fungus in the context of Covid -19 second wave epidemic in India
}

\author{
Asv Prasad * \\ Formar faculty member, Department of internal Medicine, G.I.T.A.M. Dental college, G.I.T.A.M. University campus, \\ Rushikonda, Visakhapatnam, Andhra Pradesh, India.
}

World Journal of Advanced Research and Reviews, 2021, 11(02), 173-183

Publication history: Received on 12 July 2021; revised on 14 August 2021; accepted on 16 August 2021

Article DOI: https://doi.org/10.30574/wjarr.2021.11.2.0382

\begin{abstract}
There is a sudden surge of the cases of the black fungus infection ((mucormycosis / Zygomycosis), at a time when India is reeling under a catastrophe created by the second wave of Covid -19. it is like a 'medical tsunami, ' that ravaged the health care system and the administration alike, both being caught unaware. In the beginning, there is an acute shortage of hospital beds earmarked for this infection, and the lifesaving drug, the liposomal Amphotersin B, coupled with the appalling morbidity, mortality, not to speak of the financial burden and the resource crunch, that is inflicted by it.This article briefly reviews the black fungus infection in India, in the pre and post Covid -19 eras. The risk factors for the black fungus, both Covid associated (CAR) as well as non-Covid -19 associated, are discussed. The host as well as pathogen related factors, in the pathogenesis of the black fungus infection, are explored. An alternative explanation to diabetic ketoacidosis, (DKA) in providing the acidic $\mathrm{pH}$ required by the fungus, is hypothesized, as the occurrence of the infection, in the absence of DKA, remained inexplicable. It may be noted that the acidic $\mathrm{pH}$ is responsible for making available, the free iron from the host 's serum, that is needed for the sustenance, grouth and multiplication of the fungus, as well as causing phagocytic dysfunction in the host. The different clinical presentations of mucormycosis, their salient clinical features and the management are outlined in the present article.
\end{abstract}

Keywords: Black fungus; Mucormycosis; Covid 19; Amphotericin B; Diabetes Mellitus Type 2; Immunosuppression, Rhino-Orbito-cerebral mucormycosis

\section{Introduction}

Mucormycosis is a rare but serious anigo-invasive infection caused by a group of opportunistic, saprophytic, filamentous fungi that thrive on the dead and decaying organic matter in the environment. Taxonomically, it belongs to the Phylum Mucoromycota, Order Mucorales, Family Mucoraceae, and Genus Mucor [1]. Phycomycosis or zygomycosis is first described in 1885 by Paltauf [2] and later coined as Mucormycosis in 1957 by Baker [3]. Rhizopus arrhizus is the commonest cause of mucormycosis [4].The spores are the means of transmission of the infection, which are abundant in the atmosphere and the mycelium is invasive form of the fungus. It is a deadly disease, with a 46-96\% mortality rate, depending on the underlying health condition of patients [5]. It usually affects those, whose immune system is compromised. Mucormycosis, popularly known as the black fungus infection, hit India, literally like a, bolt from the blue, which is already ravaged by the second wave of Covid -19. It is not a new disease, nor is it contagious. Prior to the Covid 19 pandemic, at least 38 countries around the world had reported cases of mucormycosis. Mucor is considered to be endemic in India, even before Covid 19 epidemic. Statistics shows, not only their prevalence but also suggest an increase in the incidence trend, even before the Covid- 19 epidemic, in India, which could be due to better awareness and diagnosis of mucormycosis. The annual incidence of cases per year is 12.9 (1990-1999 [6] , 35.6 (2000-2004) [7] , 50

\footnotetext{
${ }^{*}$ Corresponding author: Asv Prasad

Department of internal Medicine, G.I.T.A.M. Dental college, G.I.T.A.M. University campus, Rushikonda, Visakhapatnam, Andhra Pradesh, India.
}

Copyright (C) 2021 Author(s) retain the copyright of this article. This article is published under the terms of the Creative Commons Attribution Liscense 4.0. 
(2006-2007) [8].The overall increase in numbers is from 25 cases per year in 1990-2007 to 89 cases per year in 2013$2015)$ to 50 (2006-2007), The overall increase in numbers from 25 cases per year (1990-2007) to 89 cases per year 2013-2015 [9]. Baseline prevalence in India, estimated is 14 cases/100,000 people, almost 70 times the global incidence global prevalence of $0.2 / 100,000$. [10]. Sporadic cases are reported to have been seen in India, but it assumed epidemic proportions during the second wave of Covid-19 only. Mucormycosis, with prevalence of $0.27 \%$ among hospitalized Covid 19 patients, is reported by a retrospective study.[11]. The earlier cases reported in India are in diabetics, mostly associated with diabetic ketoacidosis (DKA) as against what is seen in the present epidemic, in which Covid 19 prevailed. Government of India made mucormycosis, a notifiable disease in May 2021.This, indeed is the first step to monitor for better understanding of the epidemiological trends of the black fungus infection in India. About 40,845 cases of black fungus are reported in India and the death toll from it stands at 3,129, as on 28th June 2021, as per Ministry of Health (MoH) Govt of India sources. The latest MoH bulletin on 22/7/21, puts the total reported cases at 45,374 and deaths at 4332. The black fungus is not limited to India only. Many cases have been reported from South American nations of Chile and Uruguay besides, Egypt and Iraq, in the Middle East. Besides, the neighbouring countries like Bangladesh, Pakistan and Afghanistan, cases are reported from US, UK, China and Russia and the list is not exhaustive. Thus, mucormycosis has turned into a pandemic. No staestical figures are cited for the above countries as they keep changing day by day. The majority (71\%) of the reported cases of black fungus are from India. The number of cases of the black fungus reported in India are presented in in the table 1

Table 1 Black fungus cases reported in India

\begin{tabular}{|l|l|}
\hline $21 / 5 / 21$ & 5000 \\
\hline $23 / 5 / 21$ & 9000 \\
\hline $21 / 6 / 21$ & 28200 \\
\hline $2 / 6 / 21$ & 40384 \\
\hline $21 / 7 / 21$ & 45374 \\
\hline \multicolumn{2}{|l|}{ Source: Ministry of Health, Govt of India }
\end{tabular}

Table 2 Risk factors for mucormycosis with frequency of incidence* in India

\begin{tabular}{|l|l|}
\hline Risk factor & Frequency of incidence \\
\hline Diabetes /DKA & $54-76 \% / 8-28 \%$ \\
\hline Solid organ transplantation & $0.56-1.52 \%$ \\
Renal transplant cases & $0.56-1.52 \%$ \\
\hline Malignancy especially haematological & $1-9 \%$ \\
\hline Corticosteroids & - \\
\hline Immuno suppressants & $1819 \%$ \\
\hline Chronic kidney disease & \\
\hline Patients on dialysis using iron chelators & $38 \%$ \\
\hline $\begin{array}{l}\text { Post primary tuberculosis } \\
\text { Chronic obstructive pulmonary disease (COPD) }\end{array}$ & $7-46 \%$ \\
\hline Neutropenia & \\
\hline Burns & - \\
\hline Broad spectrum antibiotics misuse & \\
\hline Voriconazole in some risk groups. & Not available. \\
\hline Nosocomial $\quad$ Oxygen delivery equipment, ventilators, & \\
\hline & \\
\hline
\end{tabular}




\section{Discussion}

\subsection{Covid - 19 associated risk factors (CAR) vs non- Covid associated risk factors}

The most of the risk factors shown in table 2 are Covid associate risk factors. They represent overall risk factors to all the different clinical types of mucormycosis risk factors. For example, the burns, trauma etc are related to cutaneous mucormycosis. So are the pre-existing lung diseases being risk factors for pulmonary mucormycosis. But the most common type of mucormycosis is Suborbital cerebral type. The rest of the risk factors are observed risk factors for Rhino-Orbito - cerebral type. Since the Covid- 19 black fungus relationship is observed quite recently. Hence the frequency of some risk factors like neutropenia, corticosteroids and immuno suppressants, whose importance can't be underestimated. Hence their frequency cannot be ascertained immediately.

\subsection{Non Covid 19 associated risk actors}

Most of these are dealt with at length but still not exhaustive. Their importance in transmitting mucormycosis can't be ignored. Besides, since most of the black fungus cases are reported following discharge from hospitalization, investigating how the infection is acquired need to be carefully evaluated to prevent outbreaks of black fungus infection. The treatment part in the hospital is emphasized rightly but no complacency to the minutes detail pertaining to the hospital cannot be over emphasized. Hence a brief enumeration of some of these with references are given below.

Contaminated tongue depressors in the immunocompromised [13]. and the use of contaminated wooden applicators used to mix drugs given to immunocompromised patients [14]. have reported too have transmitted the black fungus. cases of rhino-orbital mucormycosis following

dental procedures (tooth extraction) are reported in India [15]. Contaminated surgical dressings and non- sterile

adhesive tape has been shown to be the source of primary cutaneous mucormycosis $[16,17]$. Jain et al [18] reported the first case of localised subcutaneous mucormycosis following

intramuscular muscular injection. Some the equipment, instruments etc are mentioned under the nosocomial variety. These reports indicate how unwittingly the infection could be passed on. Some patients with mucormycosis have no identifiable risk factors. [19,20]] Primary and secondary pandemics are used by some to refer the Covid -19 and the black fungus epidemics, respectively, recognizing their inter -relationship. Invasive mucormycosis has also been associated with health-care associated outbreaks and natural disasters. [ $21,22,23$ 24,25].

\subsection{The Covid -19 connection}

- The incidence of mucormycosis in the pre- Covid-19 Era is reviewed above. The incidence is modest as compared to $140 / 100000$ cases reported at the second wave of Covid 19, in India, at its zenith.

- $\quad$ An ICMR- sponsored study is conducted between June and August in the year $20-21$, on 17,534 patients in 10 hospitals in various parts of India concluded that there is no case reported during the first wave of Covid 19. These findings are released by IC MR on 21 may 2021. There is a sudden spurt in black fungus cases at the height of the second wave of Covid 19 . Some $86 \%$ of patients with deadly fungal infection had contracted CovId-19. Surfacing of the black fungus infection after 2 to 3 weeks from the onset of the Covid19.

- $\quad$ Over 28,200 'black fungus' cases are recorded In India as on $7 / 621$, by the $\mathrm{MoH}$,

- $\quad 86 \%$, or 24,370 cases, have a history of Covid-19 and $62.3 \%$, or 17,601 , had diabetes

- $\quad$ Some $86 \%$ of patients with deadly fungal infection had contracted Covid -19.

- $\quad$ The black fungus cases occurred during May, June and July, when Covid-19 second wave is at its peak.

- The Covid-19 caused profound immune suppression and the ssmell is a precondition for black fungus infection.

- $\quad$ Black fungus infection is seen 2 to 3 weeks discharge from hospital s after Covid 19 treatment.

- Covid-19 causes endarteritis and damage to look vessels. Black fungus, being angioinvasive it's task is made easy by the Covid-19 


\section{\begin{tabular}{l|l}
$23 / 5 / 21$ & 9000
\end{tabular}}

It is observed that the incidence of the black fungus cases happened to be more in those who are hospitalized for Covid19. Thus the focus shifted to the hospitals, where the Covid-19 pts are treated before the appearance of the black fungus infection.

- $\quad$ The treatment related

- $\quad$ The hospital setup, related.

The distinction between the two is often indistinguishable, for example oxygen delivery systems and ventilators are a part of both groups.

The hospital setup:

Kathleen P. Hartnett, et al in their article on "how to investigate an outbreak of Mucormycosis in Health care setup", exhaustively dealt with each and every article that is part of hospital which is capable of transmitting the black fungus infection with references. The long list of items investigated convinces one the numerous ways, a hospital could be a source of the infection. It is out of the scope of this article to mention each and every item enlisted by them. Those Interested may refer to the exhaustive article cited. However, reference is already made to few aspects of hospital. Some of these are dealt with when non-Covid- 19 risk factors are dealt with below.

\subsection{Treatment related matters}

It is found that those hospitalized patients, who developed black fungus infection later are found to have been discharged even when the BS levels are high. Not only the Covid 19 but also the steroid doses used are contributory to the high blood sugar levels. It is well known that the black fungus needs glucose, which it utilized by the black fungus for its energy requirements and uncontrolled DM 2 thus serves the purpose of its requirements. The situation is worsened by those physicians who followed up, once they are discharged from the hospital. There is over zealous treatment in some cases where they are not even indicated. There is definite abuse of steroid due to the panic created by Covid-19. The steroid abuse is thought to have led to immuno suppression inviting the opportunistic infection, the mucormycosis.

\subsubsection{Glucocorticosteroids}

The consensus in India and the world over, is the steroids are responsible for the emergence of the black fungus, during the second wave of covid-19

Two such case reports are cited here the use of high doses of parenteral steroids steroid beyond the protocol period. A cumulative prednisone dose of greater than $600 \mathrm{mg}$ or a total methyl prednisone dose of 2-7 g given during the month before, predisposes immunocompromised people to mucormycosis [25]. Broncho pleural fistula development in the setting of novel therapies for acute respiratory distress syndrome in SARS CoV 2 pneumonia.

There are few case reports of mucormycosis resulting from even a short course (5-14 days) of steroid therapy, especially in people with DM, [26]. And Broncho- pleural fistula development in the setting of novel therapies for acute respiratory distress syndrome in SARS CoV 2 pneumonia [27].

The situation is worsened by those physicians who followed up, once they are discharged from the hospital. There is over zealous treatment in some cases where they are not even indicated. There is definite abuse of steroid due to the panic created by Covid -19 . The steroid abuse is thought to have led to immuno suppression inviting the opportunistic infection, the mucormycosis.

\subsubsection{Immunosuppressive drugs}

Not only steroids, but other immunosuppressive drugs are included in the risk factors group. Objections came from the physicians, immunologists and dermatologists who maintained that use of steroids in much larger doses and more duration never resulted in any comparable incidence of the black fungus infection, any time before. Similar is the case with immuno suppressants which are used in organ transplant cases before and after the Covid 19 and there is obvious increase as is the present situation. Likewise, opposition came from the solid organ transplant surgeons who denied seeing black fungus infection even on prolonged use of the immuno suppressants. They further contended that though black fungus infection, in organ transplant cases are seen prior to the Covid 19 pandemic, the high numbers in the second wave is something unprecedented. it is clear that neither Covid 19 or steroids or use of immuno suppressants 
or organ transplantation individually cannot induce the black fungus infection, alone, though there is no doubt in recognizing all of them as individual risk factors.

\subsubsection{The role of the delta variant}

The second wave of Covid 19 pandemic is attributed to the delta variant, which is suspected to have originated from India, which WHO called as the Variant of Concern (VOC) . CDC, tweeted on 25/7/21 that 75\%of cases of Covid- 19, in the second wave is due to the delta variant. The occurrence of the black fungus epidemic on top of the second wave of Covid-19, which is attributed to delta variant, raises an accusing finger against the delta variant, as to its role, if any, in causing the mucormycosis .Some facts about the delta variant become relevant in this context,as it's behaviour is different from the strains that caused the first wave in India.86.09\% of the infections are caused by the Delta variant (B.1.617.2).(ICMR) 9.8\% required hospitalization and fatality is observed in only $0.4 \%$ of cases. Out of the 677 patients analysed, in a study, 85 acquired COVID-19 infection after taking the first dose of the vaccine, while 592 were infected after receiving both doses of the vaccine. A total of 604 patients had received Covishield vaccine, 71 had received Covaxin and two had received Sinopharm vaccine. A total of 482 cases of the 677 cases (71\%) are symptomatic with one or more symptoms, while $29 \%$ had asymptomatic SARS CoV 2 infection. Three of the 677 people died, as per the ICMR, the delta variant had infected even those individuals who had received at least one dose of the Covid-19 vaccine. Though the delta variant exhibited some differences with earlier drains and though black fungus epidemic occurred during its time,no cause and effect is established, till date. Further, the Delta variant spread to more than a hundred countries, but nowhere, the situation turned out to be as bad as in India. This is another point against the delta variant alone. being responsible for the black fungus epidemic.

\section{Role of DM 2}

Uncontrolled diabetes mellitus is the most common underlying disease associated with mucormycosis in India $[28,29,30]$. DM is the leading risk factor for mucormycosis globally, with an overall mortality of $46 \%$. The other observation is that the infection is correlated to DM 2. Over 28,200 'black fungus' cases recorded In India as on 7/6/21, $86 \%$, or 24,370 cases, have a history of COVID-19 and $62.3 \%$, or 17,601 , had diabetes. Globally, $94 \%$ of those who had the fungal infection also suffered from diabetes. Presence of DM is an independent risk factor (Odds ratio 2.69; 95\% Confidence Interval 1.77-3.54; P $<0.001$ ) in a large 2018 meta-analysis of 851 cases of mucormycosis, and the most common species isolated was Rhizopus (48\%) [31]. The high incidence of black fungus is attributed to the high incidence of uncontrolled DM2 (57\%) as compared to America (3\%). The prevalence of diabetes in India was 7.7\% in 2016 . It is $11.2 \%$ in China, Neither China nor the US, with a similarly high prevalence of diabetes, has seen such large numbers of Mucor cases.

\subsection{Effect of combined steroids and diabetes in the covid 19 context}

One review of case reports of mucormycosis in patients with COVID-19 included 101 cases, 80 percent of whom had pre-existing diabetes mellitus, and 76 percent of whom had received glucocorticoids for the treatment of COVID-19 [32]. Another small study report noted that $21 \%$ of 210 patients with Mucor, are not diabetic and $14 \%$ had have not used steroids. The combination of DM, Steroids and Covid 19, each capable of individually causing immuno suppression in the patient enhancing the possibility of acquiring the black fungus infection.

\subsection{Role of high free iron levels}

Further, the post Covid -19 cases have high free iron levels which is one of the characteristic feature of Covid 19.These pts are discharged from the hospital before the free iron levels return to normal . It is a known fact that the black fungus requires free iron for its growth of the pathogenic mycelial form. How the free Iron is released and how the fungus avails this free iron when the host vs pathogen factors. It is already seen how acidosis releases and makes available the free iron from the protein bound iron.

\subsection{Types of mucor-mycosis}

Table 3 Main Types (with incidence in parenthesis) of mucormycosis, mode of infection and clinical features.

\begin{tabular}{|l|l|l|}
\hline Type of mucormycosis. & Mode of infection & Clinical features \\
\hline $\begin{array}{l}* \text { Rhino-Orbital- cerebral" } \\
\text { disease. } \\
(45-74 \%)\end{array}$ & $\begin{array}{l}\text { spores are deposited in the nasal } \\
\text { turbinates }\end{array}$ & $\begin{array}{l}\text { One-sided facial swelling. } \\
\text { Headache, fever nasal or sinus }\end{array}$ \\
\hline
\end{tabular}




\begin{tabular}{|l|l|l|}
\hline & & $\begin{array}{l}\text { congestion, black mark on the } \\
\text { bridge of nose etc }\end{array}$ \\
\hline $\begin{array}{l}\text { pulmonary disease } \\
3-22 \%)\end{array}$ & spores are inhaled into the lungs & $\begin{array}{l}\text { Fever,cough, shortness of breth } \\
\text { and fever. Multiple nodules } \\
\text { indulge HRCT, Pleural effusion, } \\
\text { Reverse halo sign etc. }\end{array}$ \\
\hline $\begin{array}{l}\text { Gastro-. intestinal disease } \\
(2-8 \%)\end{array}$ & spores are ingested, & $\begin{array}{l}\text { Nasea, vomiting,abdominal pain } \\
\text { and GI bleeding }\end{array}$ \\
\hline $\begin{array}{l}\text { cutaneous disease } \\
(10-31 \%)\end{array}$ & $\begin{array}{l}\text { Spores are introduced through } \\
\text { broken skin. }\end{array}$ & $\begin{array}{l}\text { Indurated plaques, necrotic } \\
\text { lesions with eschar, targeted } \\
\text { lesions,tender nodules and } \\
\text { ulcers. }\end{array}$ \\
\hline $\begin{array}{l}\text { *Most common type seen in India Other types described are Renal }(0.5-9 \%) \\
\text { and disseminated forms. (0.5-9\%) }\end{array}$
\end{tabular}

\subsection{Pathogenesis of mucormycosis in the Covid 19 context}

The host and fungus determinants in pathogenesis are shown in table 4 and are briefly discussed before summing up the pathogenesis.

Table 4 The determinants black fungus pathogenicity

\begin{tabular}{|l|l|}
\hline Host factor & Pathogen (fungus) factors \\
\hline Suppressed immunity & Virulence factors \\
\hline Weakened host defence & $\begin{array}{l}\text { Availability of nutrients } \\
\text { including Iron and Zink. }\end{array}$ \\
\hline Risk factors & Availability of energy source \\
\hline (As mentioned in table 2) & Optimum pH \\
\hline & Optimum temperature \\
\hline
\end{tabular}

\subsection{The host factors}

It is well established, that Covid-19 causes severe immunosuppression, involving both humoral and Cell mediated immunity (CMI) . This, topped up by the effect of parenteral steroids and the comorbid disease like DM2, can potentiate to cause a profound immunosuppression, as each by itself can cause individually Suppressed immunity. Besides, the host defense is further compromised by the neutropenia and lymphopenia, seen in Covid - 19, both contributing to phagocytic dysfunction and T cell dysfunction respectively. The neutrophils and monocytes are further inhibited by the acidic $\mathrm{pH}$, in which the fungus thrives. The defensive role of protein bound iron is available in host's serum is inimical to the fungal grouth and hence constitutes an important element of hosts defence. With the raising $\mathrm{pH}$, the protein bound iron dissociates into free iron raising the free to abnormal levels. This is advantageous to the fungus and disadvantageous to the host. The acute stress the patient suffers due to the prior hospitalization for Covid - 19, will adverse affect the immunity of the patient. The risk factors contributing to the infection are already discussed.

\subsection{The pathogen related factors}

\subsubsection{High-affinity iron permease (FTR1)}

Fungi can obtain iron from the host, by using high-affinity iron permeases or low-molecular-weight iron chelators (siderophores),[33,34]. Which helps iron uptake and transfers in Iron deficient environments. The FTR1 gene is highly expressed during infection by Rhizopus oryzae. FTRI belongs to reductases involved in the reduction of ferric iron to the soluble ferrous form of the iron. The reduced ferrous iron generated by the surface reductase is, in turn, captured by a protein complex consisting of a multicopper oxidase and a ferrous permease. [35,36,37]. 


\subsubsection{Rhizoferrin}

Rhizopus secretes a siderophore, Rhizoferrin. It supplies iron through a receptor-mediated, energy-dependent process. it is inefficient in obtaining iron from the serum. So, it requires the organisms' endogenous siderophores for virulence. In some Mucoralean fungi, utilize xenosiderophores, like deferoxamine to effectively obtain iron from the host.

\subsubsection{Calcineurin}

Calcineurin is calcium and calmodulin-dependent serine/threonine protein phosphatase. It is an essential virulence factor in the pathogenesis of Mucorales. It is involved in the transition of Mucor circinelloides from the yeast form to hyphae. The spores of the species are capable of inhibiting phagosomal maturation by macrophages. Calcineurin with protein kinase activity, is important for the pathogenesis of M. circinelloides.

\subsubsection{Spore coat protein}

Spore coat protein is a virulence factor found on the spore of all Mucorales. The protein plays an important role in invasion during the pathogenesis of mucormycosis. It also disrupts and damages immune cells and acts as a specific ligand for the GRP78 receptor grouth stimulant for the black fungus in vitro. Fungi can obtain iron from the host by using high-affinity iron permeases or low-molecular-weight iron chelators (siderophores) [38, 39].

\subsubsection{Glucose-regulated protein 78 (GRP78)}

It is a novel host receptor that mediates invasion and damage of human endothelial cells by Rhizopus oryzae, the commonest aetiological agent. The fungal ligand that binds to GRP78 during invasion of the endothelium belongs to the spore coating $(\mathrm{Cot} H)$ protein family. Elevated concentrations of glucose and iron, consistent with those seen during hyperglycaemia, DKA, or other forms of acidosis, enhance GRP78 expression, leading to fungal invasion and damage of endothelial cells in a receptor-dependent manner [40].

\subsubsection{Ketone reductase}

Rhizopus species have an active ketone reductase system, which may be an additional virulence factor by enhancing growth in the acidic and glucose-rich environment seen in ketoacidotic states.

\subsection{Fuel for energy metabolism}

\subsubsection{The nutrient supply}

The patients admitted for Covid 19 are discharged before the elevated levels of free serum iron, and hyperglycaemia in diabetics return to normal levels. So, the fungus has abundant supply of the nutrients for its grouth. In the name boosting immunity, Zink in high doses is consumed in the covid epidemic in India. Zink is essential to carry on the metabolic activities of the fungus The fuel for energy, the glucose, is made available in the form of hyperglycaemia, persisting in patients discharged from Covid hospital.

Optimum PH: Humaan serum supports the growth of R. Oryzae at acidic pH. (7.3 to 6.88) ( but npt at alkaline pH 7.78 8.33) [41] . In the pre-Covid Era DKA is invoked to supply acidic serum, which is believed to support the grouth of black fungus. There is no ready answer for the $\mathrm{pH}$ adjustment in mucormycosis not associated with DKA. An alternate explanation for acidic $\mathrm{pH}$ in cases, other than DKA.

\subsubsection{A hypothesis}

The author offers an alternative explanation to the production of acidic environs necessary for the fungal grouth. It is submitted that, enough it is, if the surrounding medium (the mucus secretions in the paranasal sinuses, in case of rhino cerebral mucormycosis) is acidic and not necessarily, the acidic PH of blood, (acidosis). This could be achieved locally itself, by the microbes through the "Warburg like effect "To be more explicit, the glycolysis by the microbe occurs through fermentation even in the presence of oxygen, generating the 'Lactate' which changes the $\mathrm{pH}$ of the mucus in which the fungal hyphae are bathed, to acidic $\mathrm{pH}$,which is congenial for the grouth and multiplication of the black fungus. It subserves the same functions as a systemic acidosis does (like DKA), such as liberating the free iron from the serum, inhibiting the pagocytic functions of PMN and monocytes (host defenses) besides providing the optimum pH needed for the support of the grouth and multiplication of the fungus. This explanation would perhaps provide answer to the fungal grouth in conditions other than under the DKA, which, otherwise has not been explained, in the literature. However, this hypothesis need confirmation. If this hypothesis is accepted, the embarrassment of invoking DKA, even in its absence of the same, would be saved, as is the case at present. 


\subsubsection{Optimum Temperature}

The optimum temperature for the black fungus to grow, is less than, 37 degrees centigrade (96.6, F), which corresponds to the normal body temperature.

\section{Pathogenesis of Rhino-Orbito-Cerebral mucormycosis}

- $\quad$ Spores, circulating in the air are inhaled and are deposited on the nasal turbinate bone.

- $\quad$ The PMN and monocytes phagocytise these spores.

- $\quad$ The spores are not killed, but persist in the sinuses because of dysfunction of phagocytes The virulence factors of the fungus also help the fungal survival.

- The spores germinate into the invasive mycelial forms.

- $\quad$ How the fungus obtains its nutrients, fuel for energy and optimum $\mathrm{pH}$ and Temperature are already considered above.

- $\quad$ The hyphae invade the blood vessels with the help of GP 78 receptor for which the spore coat protein acts as the ligand. and are endocytosed by the blood vessels.

- The disruption of the endothelium of the blood vessel, causes ischemic necrosis of the extravaslar matrix. The resulting black mass is characteristic that gives it the name of black fungus.

- $\quad$ Spread to orbit and brain occur through the nasopalatine and the maxillary artery.

- Invasion of orbit leads to blindness and Invasion of brain causes Stroke etc. These complications occur with such speed that the disabilities occur before the effective intervention is provided.

- How the various virulence factors of the black fungus help in the pathogenesis, is already delineated above.

\subsection{Management of Mucormycosis}

The CDC protocol for treatment of mucormycosis is given in the following table 5

Table 5 Management of Mucor mycosis

\begin{tabular}{|l|l|l|}
\hline Medical Management & Comments, dosage and precautions & $\begin{array}{l}\text { Surgical } \\
\text { Management }\end{array}$ \\
\hline Liposomal Amphotersin B & $\begin{array}{l}\text { First line drug. Dose - 5 mg/kg (10mg/kg } \\
\text { for CNS involvement) given as Iv drip in 5\% } \\
\text { dextrose over 30-60 mts time. } \\
\text { Incompatible with saline and Ringer } \\
\text { Lactate. } \\
\text { Duration 3 to 6 weeks. } \\
\text { Monitor RFT and Serum electrolytes. }\end{array}$ & $\begin{array}{l}\text { Thorough } \\
\text { debridement of the } \\
\text { involved tissue, } \\
\text { which } \\
\text { discolouration } \\
\text { black. }\end{array}$ \\
\hline $\begin{array}{l}\text { Conventional Amphotericin } \\
\text { B (deoxy cholate) }\end{array}$ & $\begin{array}{l}\text { Alternative to the above drug.Dose : 1-1.5 } \\
\text { mg/kg.Monitor same as above }\end{array}$ & \\
\hline oral Isavuconazole & $\begin{array}{l}\text { As follows up to above. 200-mg 1 tablet 3 } \\
\text { times every day for 2 days followed by 200 } \\
\text { mg daily. till physician'advice. }\end{array}$ & \\
\hline Oral Posaconazole & $\begin{array}{l}\text { Alternate followup drug. } \\
\text { Dose:300-mg delayed release tablets twice } \\
\text { a day for 1 day followed by 300-mg every } \\
\text { day till physician's advice. }\end{array}$ & \\
\hline
\end{tabular}

\section{Conclusion}

The black fungus epidemic is in the waning phase at present in India. The decline in new cases of the Covid -19 could be contributory to this decline. In retrospect, discharging from the hospitals of treated Covid-19 cases associated with DM 2 with hyperglycaemia and the high serum iron levels before they returned to normal levels, coupled with the injudicious use of corticosteroids and the combined Suppressed immunity, due to Covid- 19, DM2 and corticosteroid 
misuse, all conspired to give, epidemic proportions to an otherwise ordinary opportunistic infection, the mucormycosis, which is never seen before. A silver lining to the cloud is that, the lessons and the experiences, the epidemic taught are invaluable.

\section{Compliance with ethical standards}

\section{Disclosure of conflict of interest}

Authors have declared that no competing interests exist. The products used for this research are commonly and predominantly use products in our area of research and country. There is absolutely no conflict of interest between the authors and producers of the products because we do not intend to use these products as an avenue for any litigation but for the advancement of knowledge. Also, the research was not funded by the producing company rather it was funded by personal efforts of the authors.

\section{References}

[1] Kwon-Chung KJ. Taxonomy of fungi causing mucormycosis and entomophthoramycosis (zygomycosis) and nomenclature of the disease: molecular mycologic perspectives. Clin Infect Dis. Feb 2012; 54(1): S8-S15.

[2] Paltauf A. Mycosis mucorina. Virchows Arch Pathol Anat Physiol Klin Med. 1885; 102: 543-564.

[3] Baker RD. Mucormycosis-a new disease? J Am Med Assoc. 1957; 163: 805-808.

[4] Jeong W, Keighley C, Wolfe R, Lee WL, Slavin MA, Kong DCM, Chen SCA. The epidemiology and clinical manifestations of mucormycosis: A systematic review and meta-analysis of case reports. Clin. Microbiol. Infect. 2019; 25: 26-34.

[5] Roden MM, Zaoutis TE, Buchanan WL, Knudsen TA, Sarkisova TA, Schaufele RL. Epidemiology and outcome of zygomycosis: a review of 929 reported case. Clin. Infect. Dis. 2005; 41(1): 634-653.

[6] Chakrabarti A, Das A, Sharma A, Panda N, Das S, Gupta KL, Sakhuja V. Ten Years' Experience in Zygomycosis at a Tertiary Care Centre in India. J. Infect. 2001; 42: 261-266.

[7] Chakrabarti A, Das A, Mandal J, Shivaprakash MR, George VK, Tarai B, Rao P, Panda N, Verma SC, Sakhuja V. The rising trend of invasive zygomycosis in patients with uncontrolled diabetes mellitus. Med. Mycol. 2006; 44: 335342 .

[8] Chakrabarti A, Chatterjee SS, Das A, Panda N, Shivaprakash MR, Kaur A, Varma SC, Singhi S, Bhansali A, Sakhuja V. Invasive zygomycosis in India: Experience in a tertiary care hospital. Postgrad. Med. J. 2009; 85: 573-581.

[9] Prakash H, Ghosh AK, Rudramurthy SM, Singh P, Xess I, Savio J, Pamidimukkala U, Jillwin J, Varma S, Das A, et al. A prospective multicenter study on mucormycosis in India: Epidemiology, diagnosis, and treatment. Med. Mycol. 2019; 57: 395-402.

[10] Prakash H, Chakrabarti A. Global Epidemiology of Mucormycosis. J. Fungi. 2019; 5: 26.

[11] Patel A, Agarwal R, Rudramurthy SM, Shevkani M. Multicenter epidemiologic study of. Coronavirus diseaseassociated mucormycosis, India. Emerg Infect Dis. 2021 Sept [June 16, 2021]. 2021.

[12] Hariprasath Prakash and ArunalokeChakrabarti. Epidemiology of Mucormycosis in Indi Microorganisms. Mar 2021; 9(3): 523.

[13] Mitchell SJ, Gray J, Morgan ME, Hocking MD, Durbin GM. Nosocomial infection with Rhizopus microsporus in preterm infants: association with wooden tongue depressors [see comments] Lancet. 1996; 348: 441-3.

[14] Verweij PE, Voss A, Donnelly JP, de Pauw BE, Meis JF. Wooden sticks as the source of a pseudoepidemic of infection with Rhizopus microsporus var. rhizopodiformis among immunocompromised patients. J Clin Microbiol. 1997; 35: 2422-3.

[15] Kim J, Fortson JK, Cook HE. A fatal outcome from rhinocerebral mucormycosis after dental extractions:A case report. J. Oral Maxillofac. Surg. 2001; 59: 693-697.

[16] Gartenberg G, Bottone EJ, Keusch GT, Weitzman I. Hospital-acquired mucormycosis (Rhizopus rhizopodiformis) of skin and subcutaneous tissue: epidemiology, mycology and treatment. New Engl J Med. 1978; 299: 1115-8. 
[17] Mead JH, Lupton GP, Dillavou CL, Odom RB. Cutaneous Rhizopus infection. Occurrence as a postoperative complication associated with an elasticized adhesive dressing. JAMA. 1979; 242: 272-4.

[18] Jain JK, Markowitz A, Khilanani PV, Lauter CB. Localized mucormycosis following intramuscular corticosteroid. Case report and review of the literature. Am J Med Sci. Mar-Apr 1978; 275(2): 209-16.

[19] Mohindra S, Mohindra S, Gupta R, Bakshi J, Gupta SK. Rhinocerebral mucormycosis: the disease spectrum in 27 patients. Mycoses. Jul 2007; 50(4): 290-6.

[20] Rahman A, Akter K, Hossain S, Rashid HU. Rhino-orbital mucourmycosis in a non-immunocompromised patient. BMJ Case Rep. 2.6 Feb 2013; 013.

[21] Andresen D, Donaldson A, Choo L, Knox A, Klaassen M, Ursic C, et al. Multifocal cutaneous mucormycosis complicating polymicrobial wound infections in a tsunami survivor from Sri Lanka. Lancet. 5-11 Mar 2005; 365 (9462): 876-8.

[22] Neblett Fanfair R, Benedict K, Bos J, Bennett SD, Lo YC, Adebanjo T, et al. Necrotizing cutaneous mucormycosis after a tornado in Joplin, Missouri, 2011.N Engl J Med. 6 Dec 2012; 367(23): 221425.

[23] 10Warkentien T, Rodriguez C, Lloyd B, Wells J, et al. Invasive mold infections following combat-related injuries. Clin Infect Dis. Dec 2012; 55 (11): 1441-9.

[24] Rammaert B, Lanternier F, Zahar JR, Dannaoui E, Bougnoux ME, Lecuit M, et al. Healthcare-associated mucormycosis. Clin Infect Dis. Feb 2012; 54(1): S44-54.

[25] Hartnett KP, Jackson BR, Perkins KM, Glowicz J, Kerins JL, Black SR, et al. A Guide to Investigating Suspected Outbreaks of Mucormycosis in Healthcare. J Fungi (Basel). 24 Jul 2019; 5(3).

[26] Hoang K, Abdo T, Reinersman JM, Lu R, Higuita NIA. A case of invasive pulmonary mucormycosis resulting from short courses of corticosteroids in a well-controlled diabetic patient.Med Mycol Case Rep. 2020; 29(1): 22-24.

[27] Skiada A, Pagano L , Groll A. Zygomycosis in Europe: analysis of 230 cases accrued by the registry of the European confederation of medical Mycology (ECMM) working group on zygomycosis between 2005 and 2007 . Clin Microbiol Infect. 2011; 17(12): 1859-1867.

[28] Prakash H, Ghosh AK, Rudramurthy SM, Singh P, Xess I, Savio J, Pamidimukkala U, Jillwin J, Varma S, Das A, et al. A prospective multicenter study on mucormycosis in India: Epidemiology, diagnosis, and treatment. Med. Mycol. 2019; 57: 395-402.

[29] Patel A, Kaur H, Xess I, Michael JS, Savio J, Rudramurthy S, Singh R, Shastri P, Umabala P, Sardana R, et al. A multicentre observational study on the epidemiology, risk factors, management and outcomes of mucormycosis in India. Clin.Microbiol. Infect. 2020; 26: 944.e9-944.e15.

[30] Patel AK, Patel KK, Patel K, Gohel S. Chakrabarti, A. Mucormycosis at a tertiary care centre in Gujarat, India. Mycoses. 2017; 60: 407-411.

[31] Jeong W, Keighley C, Wolfe R. The epidemiology and clinical manifestations of mucormycosis: a systematic review and meta-analysis of case reports. Clin Microbiol Infect. 2019; 25: 2634.

[32] Singh AK, Singh R, Joshi SR, Misra A. Mucormycosis in COVID-19: A systematic review of cases reported worldwide and in India Diabetes Metab Syndr. 2021.

[33] Howard DH. Acquisition, transport, and storage of iron by pathogenic fungi. Clin Microbiol Rev. 1999; 12: 394404.

[34] Stearman R, Yuan DS, Yamaguchi-Iwai Y, Klausner RD, Dancis A. A permease-oxidase complex involved in highaffinity iron uptake in yeast. Science. 1996; 271: 1552-7.

[35] Knight SA, Vilaire G, Lesuisse E, Dancis A. Iron acquisition from transferrin by Candida albicans depends on the reductive pathway. Infect Immun. 2005; 73: 5482-92.

[36] Jung WH, Sham A, Lian T, Singh A, Kosman DJ, Kronstad JW. Iron source preference and regulation of iron uptake in Cryptococcus neoformans. PLoS Pathog. 2008; 4: e45.

[37] Anand VK, Alemar G, Griswold JA, Jr Intracranial complications of mucormycosis: an experimental model and clinical review. Laryngoscope. 1992; 102: 656-62.

[38] Gebremariam T, Liu M, Luo G, Bruno V, Phan QT, Waring AJ, Edwards JE, Jr, Filler SG, Yeaman MR, Ibrahim AS. CotH3 mediates fungal invasion of host cells during mucormycosis. J Clin Invest. 2014; 124: 237-250. 
World Journal of Advanced Research and Reviews, 2021, 11(02), 173-183

[39] Chinen K, Tokuda Y, Sakamoto A, Fujioka Y. Fungal infections of the heart: a clinicopathologic study of 50 autopsy cases. Pathol Res Pract. 2007; 203: 705-715.

[40] Gebremariam T, Liu M, Luo G, Bruno V, Phan QT, Waring AJ, Edwards JE, Jr, Filler SG, Yeaman MR, Ibrahim A. 